\title{
Determinants preventing the implementation of green growth and sustainable development in enterprises in the Slovak wood-processing industry
}

\author{
Miroslava Melichová ${ }^{1, *}$, Natália Poláková1, Mária Moresová ${ }^{1}$, and Anna Kocianová ${ }^{1}$ \\ ${ }^{1}$ Technical University in Zvolen, Faculty of Wood Sciences and Technology, T. G. Masaryka 24, 960 \\ 01 Zvolen, Slovakia
}

\begin{abstract}
Research background: Despite the fact, that green growth is one of the main goals of the European Union, a sufficient attention is still not given to it in conditions of Slovakia. The green growth represents compliance of the need to protect environment with economic development of society. So far, a comprehensive survey has not been carried out in Slovakia, which would focus on the issue of green growth and sustainable development in enterprises in the Slovak wood-processing industry.

Purpose of the article: The aim of the presented paper is to identify key external and internal determinants preventing the implementation of green growth and sustainable development in enterprises in the Slovak wood-processing industry.

Methods: Current information on the research issue was obtained through an empirical survey in the form of a questionnaire. Subsequently, the results were processed descriptively and graphically.

Findings \& Value added: The achieved results show that the key internal determinant preventing the implementation of green growth and sustainable development in enterprises in the Slovak wood processing industry is the orientation of production to the end of the production process in the context of environmental pollution. The enterprises consider insufficient state support to be the main external determinant.
\end{abstract}

Keywords: green growth; indicators of green growth; wood-processing industry; Covid-19

JEL Classification: $M 21 ; M 29 ; Q 56$; Q57; Q59

\footnotetext{
${ }^{*}$ Corresponding author: xvetrakova@is.tuzvo.sk
} 


\section{Introduction}

In recent decades, green growth (GG) has clearly dominated the political programs making of the OSN, the European Union and in many countries (Parrique et al., 2019). In the first half of 2020, the COVID-19 pandemic led to a reduction in human mobility, which resulted in an economic downturn and a reduction in greenhouse gas and air pollutant emissions (Liu et al., 2020). The COVID-19 pandemic has shown the fatal consequences of unpreparedness for unforeseen situations in all areas of life. If the growth of individual national economies fails to recover in a sustainable way, they will become even more unprepared and vulnerable, as they will face a climate crisis in the near future. The planned incentives for economic recovery after the COVID-19 pandemic should certainly not limit the efforts made so far by governments, the resources already allocated, as well as the policies aimed at climate change and protection of life (Chapman, 2020). For this reason, the European Union has developed several instruments, such as Next Generation EU, HORIZON 2020, HORIZON EUROPE, which aim to support research and innovation (European Comission, 2020). The goals of sustainable development of the OSN as well as the climate goals of the European Commission are based on the theory of green growth and reduction of greenhouse gas emissions (Hickel et al., 2019). There are many definitions of GG, however the most commonly used is the one defined by OECD (Capasso et al., 2019). OECD (2011) defines green growth as the goal to foster economic growth and development while ensuring that natural resources are used in a sustainable way and to continue providing the resources and environmental services on which our welfare relies. The concept of green growth is often combined with bioeconomy that focuses on reusing biomass streams and creating high valueadded products. The bioeconomy is generally merged with global growth and technological development (Vogelpohl et al., 2021). In connection with the bioeconomy, other sustainable concepts are often inflected, such as green economy or circular economy, between which there are mutual relations. The wood-processing industry WPI) in Slovakia represents woodworking, furniture and pulp and paper industry. WPI is an important industry, that affects national economy and social development. Wood is an important renewable resource not only for the Slovak economy (Zhang et al., 2018). The aim of the represented paper is to identify key external and internal determinants preventing the implementation of green growth and sustainable development in enterprises in the Slovak wood-processing industry.

\section{Methodology}

The methodology of the submitted paper consisted of three phases. The first phase was focused on the analysis of secondary sources on the issue of green growth and sustainable development in the wood-processing industry in Slovakia. In this phase, methods of scientific work such as summarization, synthesis of knowledge and methods of analogy and deduction were used. The second phase was focused on the analysis of primary sources obtained by realization of empirical research, the method of questioning. The questionnaire was focused on mapping the current state of green growth in the wood-processing enterprises and identifying the key external and internal determinants preventing the development of green growth and sustainable development in the WPI enterprises in Slovakia. The data of the questionnaire survey were evaluated in a descriptive manner, numerically and graphically. In the third phase, the results were evaluated through analogy, deduction and summarization of the acquired knowledge. 


\subsection{Data collection and survey sample}

The starting point for acquisition of knowledge about green growth and sustainable development was the realization of an empirical survey. The questionnaire was sent to 5,315 business entities and 164 respondents took part in the survey. An electronic questionnaire was sent to enterprises in the wood-processing industry. The questions of the questionnaire were designed so that it was possible to find out the current state of the research issue and identify internal and external determinants preventing the development of green growth and sustainable development in the wood-processing industry in Slovakia. The questionnaire was divided into five sections, as follows: section A - 4 questions: Identification questions (A1 A4); section B - 9questions: Business orientation towards green growth (B5 - B13); section $\mathrm{C}-1$ question: Internal determinants $(\mathrm{C} 14)$; section $\mathrm{D}-1$ question: External determinants (D15); section E - 3 questions: Indicators of green growth (E16). The questions in the section A were focused on the determination of size of the enterprise, length of operation on the market, legal form of business. The questions in the section B were aimed at determination whether the enterprise was oriented towards green growth and used means to achieve the sustainability of the enterprise. The questions in the sections $\mathrm{C}$ and $\mathrm{D}$ were aimed at identifying the internal and external determinants preventing the development of green growth and sustainable development in the wood processing enterprises. The questions in the section $\mathrm{E}$ were focused on indicators of green growth, whether they were implemented by the surveyed enterprises and whether they would help them increase their performance and sustainability. Based on the literature review, the following research questions were formulated:

Research question ( $\left.\mathbf{V}_{1}\right)$ : Have most of wood-processing enterprises in Slovakia been operating on the market for more than 20 years, which relates to the long-term tradition of the industry in Slovakia?

The wood-processing industry has a long tradition in Slovakia and represents one of the most important traditional industries on which it is possible to build the development of ecoinnovation in the conditions of the Slovak Republic (Šulyová and Koman, 2020).

Research question ( $\left.\mathbf{V}_{2}\right)$ : Do most of Slovak enterprises in the wood-processing industry pay sufficient attention to the issue of green growth and sustainable development?

Enterprises focus on the underutilized national economic potential of Slovakia, based on the natural wealth of renewable sources of raw materials and energy (Johnsson et al., 2019; Malá et al., 2017).

Research question ( $\left.\mathbf{V}_{3}\right)$ : Is the orientation of producers in the context of environmental pollution at the end of the production process the key internal determinant preventing the development of green growth and sustainable development in the Slovak wood-processing industry?

OECD (2010) presents that, in the interest of sustainability, the transformation of today's industry is essential, which means attention shifting from the end of production processes associated with pollution control to the beginning. An important starting point for this transformation is the design of production processes, products and services.

Research question ( $\left.\mathbf{V}_{4}\right)$ : Is insufficient state support the key external determinant preventing the development of green growth and sustainable development in the woodprocessing industry?

The European Union has defined a basic strategy to alleviate the current crisis by promoting green growth and sustainability. Such a procedure should be applied by all member states, including Slovakia. From the assistance provided so far by the government of the Slovak Republic to mitigate the consequences of the crisis, a minimum of funds was directed at the development of green growth (Szovics, 2020).

Research question (V5): Do most of wood-processing enterprises in Slovakia have implemented indicators of green growth? 
If enterprises do not use indicators, they will not have enough opportunities and they will also not be sustainable without people protecting natural capital, which can be a problem for wood-processing enterprises (Acosta et al., 2020).

Research question (V6): Do most of wood-processing enterprises in Slovakia share the opinion that the implementation of indicators of green growth will contribute to the growth of sustainability of enterprises in the sector?

Sustainability is one of the most important benefits of the wood-processing industry to the bioeconomy. This ensures the preservation of natural resources for future generations in order to meet their needs with the secondary effect of reducing the greenhouse gas content in the atmosphere (Šulyová and Koman, 2020).

\section{Results}

\section{Evaluation of identification data}

The survey was participated by the smallest wood-processing enterprises with 10-49 employees $(40 \%)$ and the least large enterprises with 250 or more employees $(6,10 \%)$. $26,70 \%$ of micro wood-processing enterprises and $27,30 \%$ of medium-sized woodprocessing enterprises with 50-249 employees participated in the survey. In terms of legal form, the most numerous groups are represented by WPI enterprises doing business through a limited liability company $(72,70 \%)$. On the contrary, in the empirical survey, the share of enterprises in the survey sample is the lowest with the legal form of cooperatives $(6,10 \%)$. The second least numerous groups represented in the survey sample with a rate of $6,70 \%$ are joint-stock companies and 14,50\% are self-employed.

Tradition of Slovak wood-processing enterprises on the market

The results showed that $57,3 \%$ of Slovak WPI enterprises have been operating on the market for more than 20 years. The remaining shares are WPIs with the length of operation of $11-19$ years $(24,4 \%), 6-10$ years $(8,6 \%)$ and less than 5 years $(9,7 \%)$. Given that more than $50 \%$ of Slovak WPI enterprises have been operating on the market for more than 20 years, it can be stated that the wood-processing industry has a long tradition in Slovakia. An overview of the answers to the question according to percentages is given in Figure 1.

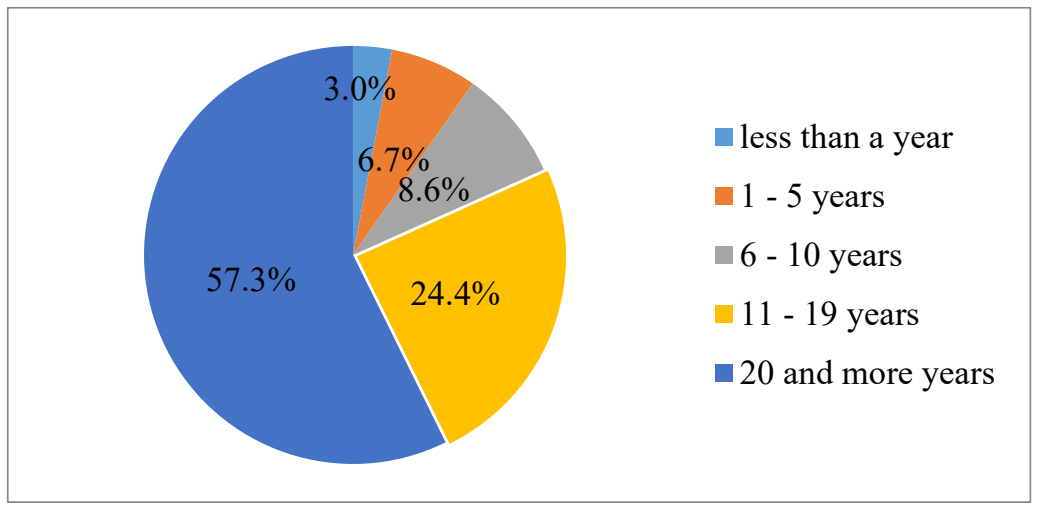

Figure 1. Length of operation of Slovak WPI enterprises on the market

Source: developed by authors (2021)

Attention of Slovak wood-processing enterprises towards green growth and sustainable development

The results showed that $36 \%$ of WPI enterprises use technology innovation to save energy. However, almost a quarter (21\%) of WPI enterprises surveyed do not use any energy savings. Detailed percentages are presented in Figure 2. Following the research question V2, 
respondents also answered other questions. Figure 3 presents the percentages where respondents indicated that they do not use or apply the area in their business, which is considered as not paying enough attention to green growth and sustainable development (SD). Most of the surveyed enterprises do not use EMAS registration $(89,6 \%)$ or EMS $(86,0 \%)$, do not label their products with an eco-label $(73,2 \%)$ and also do not apply the principles of SD $(52,4 \%)$. On the other hand, a minority of the enterprises do not recycle waste $(23,8 \%)$, nor do they use technologies that are more environmentally friendly $(48,8 \%)$. It follows from the above that considering the current environmental burden on our planet, enterprises in the wood-processing industry should pay more attention to green growth and sustainable development.

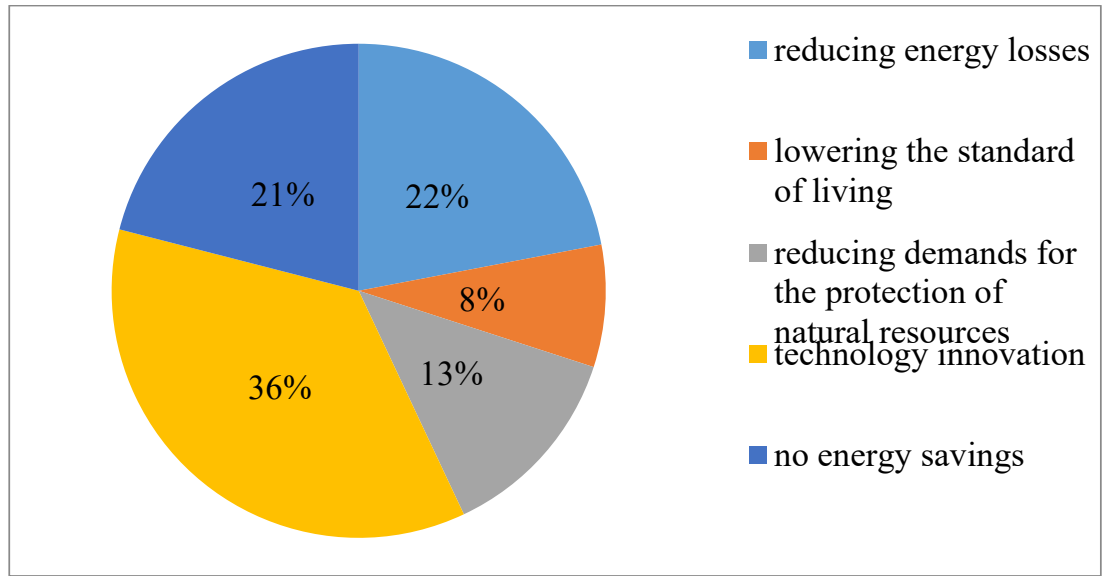

Figure 2. Energy savings in companies

Source: developed by authors (2021)

more environmentally friendly technologies

application of the principle of sustainability

waste recycling

environmental labeling of products

use of the EMS system

EMAS registration

\section{$48.8 \%$}

$52.4 \%$

$23.8 \%$
$73.2 \%$

$86.0 \%$

$89.6 \%$

Figure 3. The rate does not use tools to support green growth and sustainable development

Source: developed by authors (2021)

Key internal determinants preventing the development of GG and SD in WPI in Slovakia

As the picture presents, the orientation of production towards the end of the production process in the context of environmental pollution (EP) (50\%) is the main determinant that prevents the development of GG and SD in WPIenterprises. The second most common determinant that prevents the implementation of GG and SD is the lack of funds $(32,3 \%)$. Determinants: are not interested in buying and introducing new technologies, they are not interested in innovating or investing in research and development reached less than $7 \%$. 


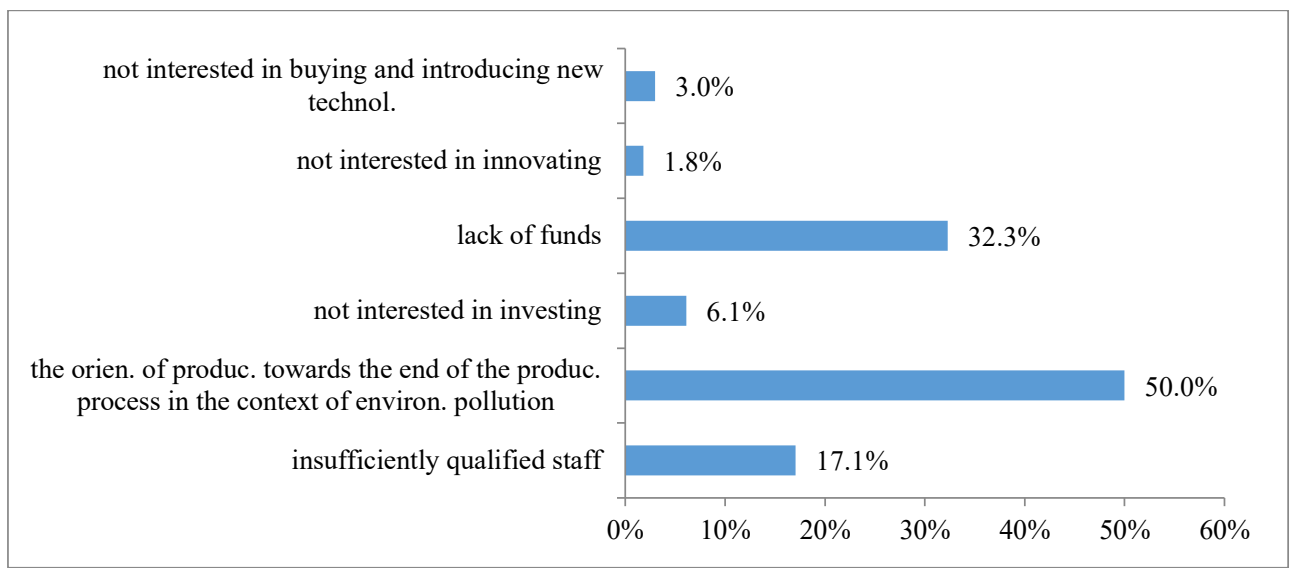

Figure 4. Internal determinants preventing the development of GG and SD in WPI in Slovakia Source: developed by authors (2021)

Key external determinants preventing the development of GG and SD in WPI in Slovakia

The results of the survey showed that $54,3 \%$ of WPIenterprises in Slovakia consider insufficient state support as the key determinant preventing the development of their enterprises. The second most commonly mentioned determinant is administrative complexity $(36,6 \%)$, followed by insufficient financial support from the state $(34,1 \%)$. The achieved results clearly confirm the insufficient support from the Slovak government for WPI enterprises.

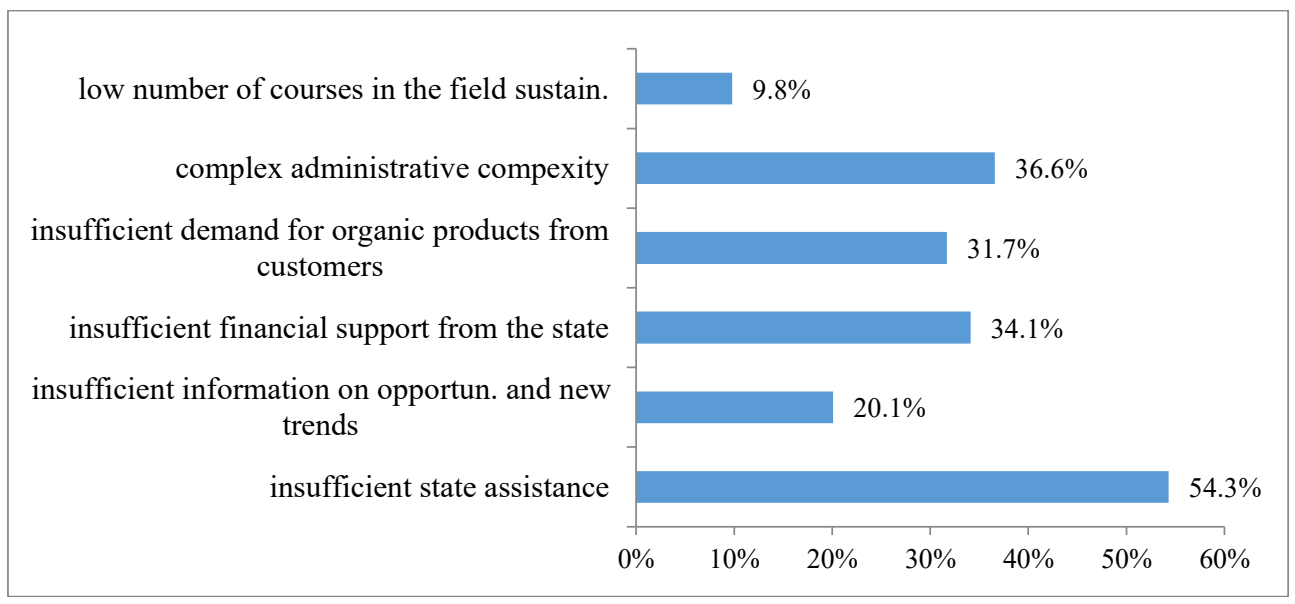

Figure 5. External determinants preventing the development of GG and SD in WPI in Slovakia Source: developed by authors (2021)

\section{Implementation of indicators of green growth in WPI enterprises in Slovakia}

Two questions from the questionnaire related to the V5 research question. One of the questions was whether the enterprises knew what the indicators of green growth were $62,2 \%$ said they did not know what it was (Figure 6). The second question on the research question focused on whether WPI enterprises have indicators of green growthimplemented. The results showed that $92,1 \%$ of the WPI enterprises do not have them implemented (Figure 7). It follows from the above that most Slovak wood-processing enterprises do not have implemented the indicators of green growth. 


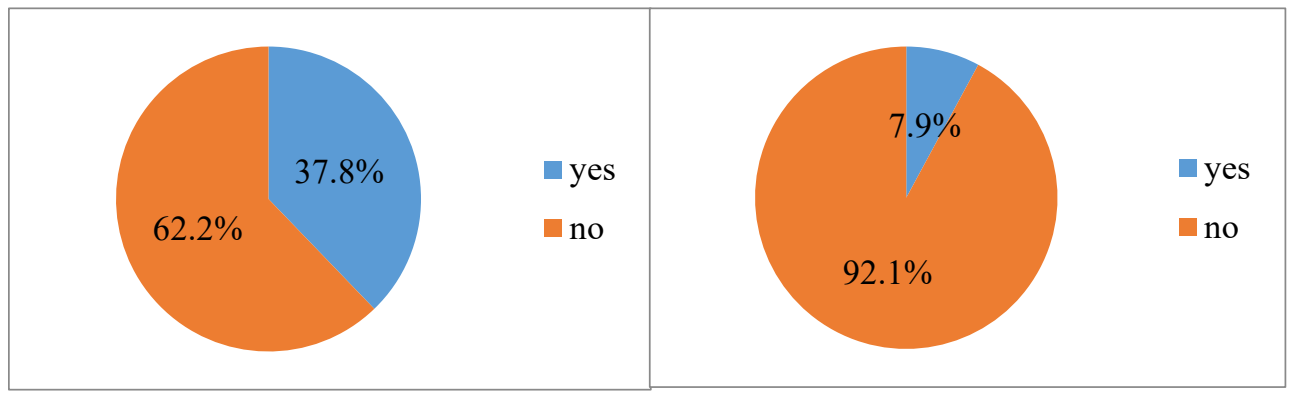

Figure 6. Knowledge of GG indicators

Source: developed by authors (2021)
Figure 7. Rate of introduction of GG indicators

Source: developed by authors (2021)

\section{Impact of indicators of green growth on sustainability of WPI enterprises}

As the results of the survey showed, 74\% of WPI enterprises in Slovakia are inclined to the opinion that the implementation of green growth indicators will contribute to the growth of sustainability of enterprises in this sector (Figure 8). The remaining 26\% of WPI enterprises are of the opinion that the implementation of indicators of green growth would not contribute to the growth of their sustainability. The direction of the survey presupposes confirmation of the research question.

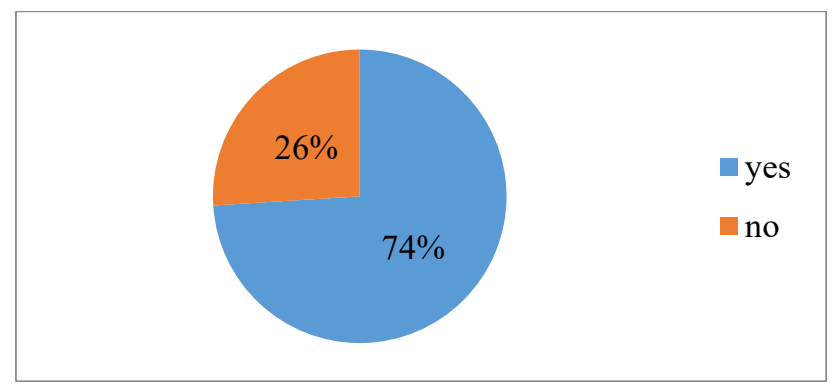

Figure 8. Respondents' attitude to the introduction of GG indicators in their enterprises

Source: developed by authors (2021)

\section{Discussion}

Based on the results of the survey, it can be stated that the wood-processing industry in Slovakia has a long-term tradition. The achieved results correspond to the authors' research Šulyová and Koman (2020) who found out that the wood-processing industry has a long tradition in Slovakia and represents one of the most important traditional industries on which the development of eco-innovation in the conditions of the Slovak Republic can be built. Lorincová et al. (2020) agree with these results, who state that the wood-processing industry is an important part of industry in the Slovak Republic and is relatively independent of the importance of natural resources and allows the development of small and medium-sized enterprises. Given the current environmental burden on the planet Vetráková and Sedliačiková (2020) point out that ensuring sustainability is undoubtedly the most important contribution of the wood-processing industry to the green economy. The survey also showed that enterprises in the wood-processing industry should pay more attention to green growth and sustainable development. At the time of current COVID crisis, it is essential increased attention to be paid to the study of internal determinants (Birbirenko et al., 2020). The basic 
internal determinant preventing the development of green growth and sustainable development in the wood-processing industry in Slovakia is the orientation of production in the context of environmental pollution at the end of the production process. OECD (2010) presents that in the interest of sustainability, the transformation of today's industry is essential, which means attention shifting from the end of production processes associated with pollution control to the beginning. An important starting point for the transformation is the design of production processes, products and services. Products can be redesigned to be used longer, to be repaired, upgraded or reworked (Sarkodie et al., 2016). The results of the survey showed that the key external determinant preventing the development of green growth and sustainable development in the wood-processing industry is insufficient support from the state. Szovics (2020) alleges that, of the aid granted so far to mitigate the effects of the crisis, only a minimum of funding has gone to developing green growth. Although the Slovak Republic is officially committed to greening the economy, specific rules and tools for its application at the national or regional level are absent (Halaj et al., 2018). For the effective implementation of green initiatives and indicators, regular monitoring and evaluation of the effectiveness of implemented tools and implemented measures is necessary. Evaluation through GG indicators helps to determine the development trend and allows focusing on the areas that require the most attention from the point of view of the green economy (Sedliačiková et al, 2019). Hojsik et al. (2020) points out that the fact that indicators of green growth have not been set for some areas yet, can be considered as the issue of not using them. This means that the area is important for assessing the path towards sustainable development, nevertheless, sufficiently representative indicators have not been known yet to quantify the fact. For the sustainability of an important renewable resource, such as wood, it is important to significantly increase the efficiency of its processing. Much of this raw material ends up in the wood-processing industry, where it is used to make pulp, paper, construction and furniture lumber, floors and many other products. (Ondrejka et al., 2020). The results of the survey indicate that most wood-processing enterprises in Slovakia share the view that the introduction of indicators of green growth will contribute to the growth of sustainability of enterprises in the sector. As added by Malá et al. (2017) the implementation of green activities in wood-processing enterprises will help reduce the environmental impact of their products and processes and improve their performance and sustainability.

\section{Conclusions}

The aim of the paper was to map the current state of green growth in WPI in Slovakia with regard to defining main internal and external determinants preventing the implementation of green growth and sustainable development in enterprises in the industry. The results showed that up to $92,1 \%$ of the enterprises do not have green growth indicators implemented and $62,2 \%$ of the enterprises do not even know what it is. However, up to $74 \%$ of respondents think that if they had indicators of green growth implemented, it would help increase the sustainability of their enterprises. WPI in Slovakia has a long-term tradition, which is confirmed by the results of the survey, as more than half of the enterprises have been operating on the market for more than 20 years. When asked about their attention to green growth, more than half of respondents said that they do not use environmental management system or environmental management and audit system in their enterprises. They also stated that they do not apply the SD principle or display eco-labels on their products. On the positive side, up to $76,2 \%$ of wood-processing enterprises apply for waste recycling. It should be noted that most of WPI enterprises in Slovakia consider the orientation of production in the context of environmental pollution to the end of the production process and not to the beginning as it should be, as the key internal determinant preventing the development of 
green growth and sustainable development. They consider insufficient state assistance to be the key external determinant, which is also confirmed by the determinants placed in the second and third place, namely complicated administrative complexity and insufficient financial support from the state. In the future, it is necessary to remove the limitations of research, i.e. to obtain a sufficient number of completed questionnaires so that it is possible to generalize the results to the entire Slovak wood-processing industry. After completing the empirical survey, the vision is to design indicators of green growth that will contribute to the sustainability of enterprises in the wood-processing industry.

\section{Acknowledgements}

This research was funded by Slovak Research and Development Agency, grant number APVV-18-0520 and by Scientific Grant Agency VEGA, grant number VEGA 1/0161/21. Also by fund of KEGA project no. KEGA 005TU Z-4/2020 and IPA projects of International project agency IPA 09/2021.

\section{References}

1. Acosta, A. L., Maharjan, P., Peyriere, H. M., \& Rusyan, J. (2020). Natural capital protection indicators: Measuring performance in achieving the Sustainable Development Goals for green growth transition. Environmental and Sustainability Indicators, 8, 100069.

2. Birbirenko, S., Zhadanova, Y., \& Banket, N. (2020). Influence of pandemic of coronavirus resilience of Ukrainian enterprises. Economic Annals-XXI, 183, 5-6.

3. Capasso, M. (2021). Degrowth or green growth: A reflection on the Recent public discourse in Norway. Sustainability, 13, 1-15.

4. European commission. (2020, October 5). Circular Economy Action Plan. https://ec.europa.eu/environment/pdf/circulareconomy/new_circular_economy_action_ plan.pdf

5. Halaj, D., Sedliačiková, M., \& Malá, D. (2018). Customer Behavior on the Slovakian Roundwood Market: A Case Study. Bioresources, 13(3), 6003-6020.

6. Hickel, J., \& Kallis, G. (2019). Is Green Growth Possible? New Political Economy, 25, 469-486.

7. Hojsík, M., Hegyi, L., \& Remeta, J. (2020, October 5). Plán ZELENEJ obnovy. https://www.incien.sk/wp-content/uploads/2020/07/Zelen\%C3\%A1Obnova.pdf

8. Chapman, A. (2020). Impacts of Covid-19 on a Transitioning Energy System, Society and International Cooperation. Sustainability, 12, 8232.

9. Johnsson, S., Andersson, E., Thollander, P., \& Karlsson, M. (2019). Energy savings and greenhouse gas mitigation potential in the Swedish wood industry. Energy, 187(15), 115919.

10. Liu, Y. C., Kuo, R., \& Shih, S. (2020). Covid-19: The first documented coronavirus pandemic in history. Biromedical Journal, 43(4), 328-333.

11. Lorincová, S., Stachová, K., Stacho, Z., \& Joniaková, Z. (2020). Defining the Differences in Corporate Culture in Woodprocessing and Forest Enterprises. Bioresources, 15(2), 3320-3343.

12. Malá, D., Sedliačiková, M., Dušak, M., Kaščáková, A., Musová, Z., \& Klementová, J. (2017). Green Logistics in the Context of Sustainable Development in Small and Medium Enterprises. Drvna Industrija, 68(1), 69-79. 
13. Malá, D., Sedliačiková, M., Kaščáková, A., Benčiková, D., Vavrová, K., \& Bikár, M. (2017). Green Logistics in Slovak Small and Medium Wood-Processing Enterprises. Bioresources, 12(3), 5155-5173.

14. OECD. (2010, October 5). Eco-Innovation in Industry: Enabling Green Growth OECD. http://browse.oecdbookshop.org/oecd/pdfs/browseit/9209061E

15. OECD. (2011, October 5). Towards Green Growth, Paris: Organization for Economic Cooperation and Development. https:/www.oecd.org/env/towards-green-growth9789264111318-en.htm

16. Ondrejka, V., Gergel', T., Bucha, T., \& Pástor, M. (2020). Innovative methods of nondestructive evaluation of log quality. Central European Forestry Journal, 66(1), 3-13.

17. Parrique, T., Barth, J., Briens, F., \& Spangenberg, J. H. (2019, October 5). Decoupling Debunked. Evidence and arguments against green growth as a sole strategy for sustainability. A study edited by the European Environment Bureau EEB. https://eeb.org/library/decoupling-debunked/

18. Sarkodie, S. A., \& Owusu, P. A. (2021). Escalation effect of fossil-based $\mathrm{CO}_{2}$ emissions improves green energy innovation. Science of the Total Environment, 785.

19. Sedliačiková, M., Stroková, Z., Drábek, J., \& Malá, D. (2019). Controlling implementation: What are the benefits and barriers for employees of wood processing enterprises. Acta Facultatis Xylologiae Zvolen, 61(2), 163-173.

20. Szovics, P. (2020, October 5). Bude rok 2021 začiatkom zeleného ekonomického rastu? https://www.trend.sk/technologie/bude-rok-2021-zaciatkom-zeleneho-ekonomickehorastu

21. Šulyová, D., \& Koman, G. (2020). The Significance of IoT Technology in Improving Logistical Processes and Enhancing Competitiveness: A Case Study on the World's and Slovakia's Wood-Processing Enterprises. Sustainability, 12, 7804.

22. Vetráková, M., \& Sedliačiková, M. (2020). Indikátory zeleného rastu pre kvantifikáciu efektivnosti a výkonnosti drevospracujúceho priemyslu v Slovenskej republike. TUZVO.

23. Vogelpohl, T., Beer, K., Ewert, B., Perbandt, D., Töller, A. E., \& Böcher. (2021). Patterns of European bioeconomy policy. Insights from a cross-case study of three policy areas. Environmental Politics, Early access

24. Zhang, K., Peng, W., \& Wang, L. (2018). Efficiency analysis of wood processing industry in China during 2006-2015. IOP Conference Series: Materials Science and Engineering, 332(5), 052062. 